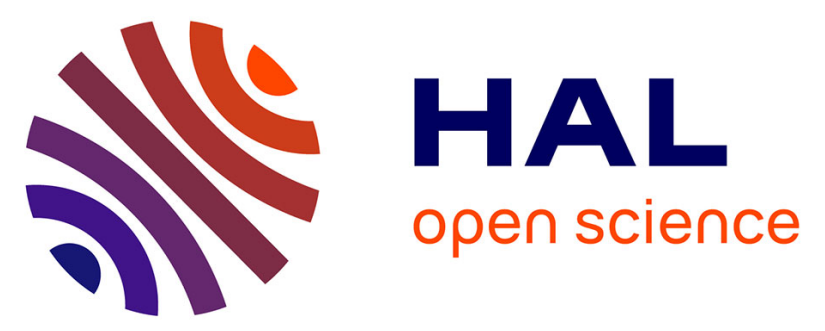

\title{
Comparing Sustainable Performance of Industrial System Alternatives by Integrating Environment, Costs, Clients and Exploitation Context
}

Yann Leroy, François Cluzel, Guillaume Lamé

\section{- To cite this version:}

Yann Leroy, François Cluzel, Guillaume Lamé. Comparing Sustainable Performance of Industrial System Alternatives by Integrating Environment, Costs, Clients and Exploitation Context. ASME 2014 International Design Engineering Technical Conferences \& Computers and Information in Engineering Conference - IDETC/CIE 2014, Aug 2014, Buffalo, New-York, United States. Paper No. DETC2014-34882, 10.1115/DETC2014-34882 . hal-01144384

\author{
HAL Id: hal-01144384 \\ https://hal.science/hal-01144384
}

Submitted on 21 Apr 2015

HAL is a multi-disciplinary open access archive for the deposit and dissemination of scientific research documents, whether they are published or not. The documents may come from teaching and research institutions in France or abroad, or from public or private research centers.
L'archive ouverte pluridisciplinaire HAL, est destinée au dépôt et à la diffusion de documents scientifiques de niveau recherche, publiés ou non, émanant des établissements d'enseignement et de recherche français ou étrangers, des laboratoires publics ou privés. 


\title{
Comparing sustainable performance of industrial system alternatives by integrating environment, costs, clients and exploitation context
}

\author{
Yann Leroy ${ }^{11}$, François Cluzel ${ }^{1}$ and Guillaume Lamé1 \\ ${ }^{1}$ Ecole Centrale Paris, Laboratoire Genie Industriel, Chatenay-Malabry, France
}

\begin{abstract}
Life Cycle Assessment (LCA) is a methodology to assess environmental performances of products throughout their life cycles. Traditionally, LCA-based decision-making focuses on environmental impacts, excluding customer expectations and economic considerations. Moreover, it usually uses generic data while environmental performances of industrial systems often depend on local contexts. The aim of this paper is to provide a comprehensive framework to identify the solution most adapted to a specific context, considering environmental, economic and commercial aspects. First, environmental performances of competing products are compared thanks to LCA. A sensitivity analysis highlights influential parameters on which operational scenarios are built. Costs are then incorporated into a set of exploitation scenarios. Second, matrix-based approach is used. Products are ranked according to several client profiles. The most suitable solution for a given context is identified. This framework is applied on three burners for forge furnaces. Results show that client profiles and operational contexts (namely client expectations, location and resources availability and costs) affect choices.
\end{abstract}

Keywords: Sustainable Industrial System, Life-Cycle Assessment, Voice of Customer, Exploitation scenarios, Operating local contexts.

\section{Introduction}

Sustainable issues are of growing interest when designing and/or defining the most relevant technological solution to implement. Large energy-consuming industrial systems are particularly concerning as they may be implemented worldwide in very different exploitation contexts, whether it concerns economic, environmental or social impacts.

Nevertheless, environmental performances are sensitive to the external environment, e.g. geographical location, resource accessibility and regulations. High uncertainties may exist in the life cycle of an industrial system, limiting the ability to obtain accurate LCA results [1]. Moreover, sustainable decision-making cannot disconnect environmental performances from client's expectations and economic analysis. In this case the solution would be limited in all dimensions [2].

In this paper, the authors deal with the implementation of context-based Life Cycle Assessment (LCA), economic costs and clients' expectations into a structured matrix-based approach to identify the best industrial solution for a given context. This approach is applied to three alternatives of forge furnace burners. We first introduce methodological elements that are then applied on forge furnace burners. Methodology and results are then discussed. Finally some concluding remarks and perspectives are given.

\section{Methodology}

${ }_{1}$ Corresponding author: yann.leroy@ecp.fr 
When dealing with industrial systems, economic and environmental impacts may vary from one geographical site to another [3]. Making decisions based on sustainable considerations is thus a hard task. We already proposed some contributions to make the environmental evaluation of such systems more reliable [1]; however we only considered environmental aspects.

Life Cycle based decision-making implies the combination of environmental, economic and clients' aspects. In this context a framework is proposed to deal with this decision on technology. As aforementioned, technology performances may be highly sensitive to local operational context till resource availability is of high interest.

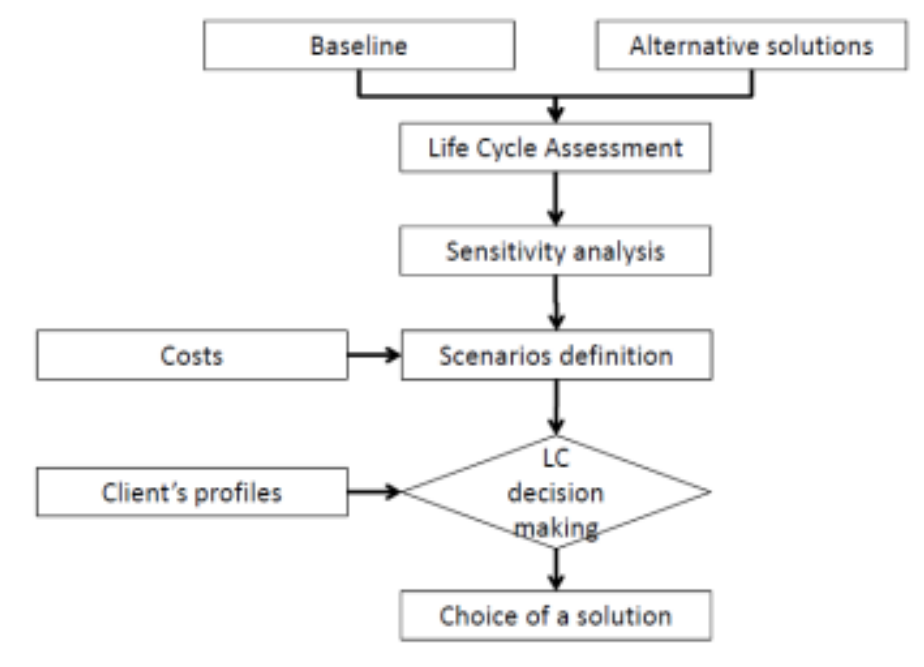

Figure 1. Methodological Framework for decision-making

The proposed approach is illustrated on Figure 1. First a set of technological solutions to compare is defined. One of these solutions is taken as a reference (e.g. the historical solution or the most implemented one). This solution is called "Baseline", the others are alternative solutions. A comparative LCA of these solutions is then performed by fixing context parameters to identify the most relevant variables. Once done and thanks to one-way sensitivity analysis, a set of scenarios is built to characterize the operational context. A new comparative LCA is then performed to define the most relevant context-technology couple from these scenarios.

In addition, environmental issues cannot be disconnected from economic aspects. Indeed, the most environmentally-friendly solution may involve prohibited costs. Moreover, such decision-making implies that the technology will be exploited over a long period. Operational costs may also highly contribute to the investment decision. Several works coupled LCA with Life-Cycle-Costing [2][4][5], that imply a detailed knowledge about the system and its exploitation. We propose alternatively to limit the cost integration to capital expenditure (CAPEX) and operational expenditure (OPEX). While the first focuses on investment costs, the second includes maintenance cycles and resources consumption. CAPEX and OPEX are thus calculated and associated to each scenario.

Finally, the values system for the decision process may vary from one client to another. Thus, for the same context, the most appropriate technological solution may also vary. To overcome these limitations and to shed light on the decision-making process, technological solutions are evaluated through the integration of client's preferences [6]. To do so, realistic clients' profiles are constructed considering environmental and economic aspects. The three dimensions, e.g. environmental performance, economic performance and voice of customer are aggregated using several matrices that measure weighted indicators based on economic, environmental or exploitation parameters.

This approach is applied in the next section on three technological solutions for forge furnace, considering four exploitation scenarios (US, France, Germany, Japan) and three clients' profiles. The case study was provided by the FIVES Group, an industrial engineering Group, which designs and supplies process equipment, production lines and turnkey plants for the world's largest industrial groups in the aluminium, steel, glass, automotive, logistics, cement and energy sectors. 


\section{LCA of the forge furnace}

In this section, the Baseline comparative LCA is performed. Three competing solutions of burners for the forge furnace (see Figure 2) are compared. with respect to ISO 1404X standards [7], [8]. The case study relates to the forging process which involves applying compressive forces to deform steel pieces. Steel pieces need to be heated before being hammered, pressed or rolled. To do so, the heat in the furnace is provided by one or several burners. At present three main alternative solutions for combustion systems are available:

a Cold Air System which uses ambient air and fuel in the combustion process and employs proportionally greater excess air rates as the operating rate decreases,

an Oxy-fuel System which consumes pure oxygen, and

a Regenerative System which recovers waste heat from furnace exhaust gases and preheats combustion air, to significantly increase efficiency over conventional burners or burners with recuperators.

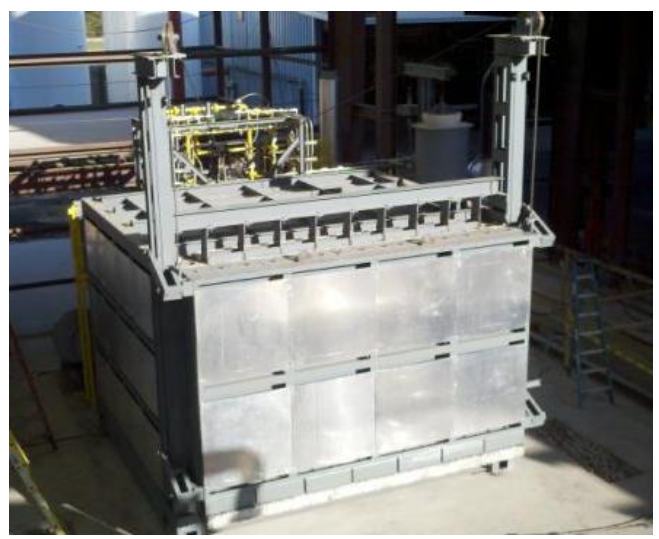

Figure 2. Example of a forge furnace

\section{Goal and scope}

The objective of this study is to define the most relevant technology to implement in a forge furnace according to its geographical context. The main technological choice focuses on the burner; however it cannot be disconnected from the forge furnace. In this context, the system boundaries integrate a cradleto-grave perspective. This includes the raw materials extraction and preparation, the manufacturing phase, the transportation phase, the operational phase (comprising maintenance cycles) and the End-of-Life treatments for both the burners and the forge furnace. The lifespan of the forge furnace is assumed to be 25 years regardless of the considered technology. Several parts of the furnace, such as refractory fibers and furnace hearth, along with the regenerative burner heat transfer media are assumed to be replaced yearly with respect to the maintenance planning. The functional unit of the system is defined as "to provide and maintain a temperature of $2300^{\circ} \mathrm{F}$ uniformly distributed in the furnace". The system boundaries are depicted in Figure 3.

\section{Life Cycle Inventory (LCI)}

Primary data were gathered from the Fives Group. Secondary data, related to other systems, were extracted from the Ecoinvent V2.0 database [9]. The $\mathrm{LCl}$ is presented in Table 1. The $\mathrm{LCl}$ is broken down according to the different life cycle phases and comprises consumptions and emissions for the different components, the manufacturing phase, the distribution phase, the operational phase and the End-Of-Life (EOL). For the purpose of comparison, the three technologies for burners are essentially designed in Europe and can be installed worldwide according to the forge furnace location. This assumption is taken as the baseline for our case study. Thus, raw materials distribution and energy consumption for the manufacturing phase are extracted from generic data that represents and corresponds to a European context. The study focuses 
on burners technologies. This implies that the forge furnace design parameters such as dimensions and yearly production (5,500 ton/year) for example, are fixed and the same for the three alternatives.

\section{Life Cycle Impact Assessment (LCIA)}

The LCIA was performed with Simapro 7.2 software. As above-mentioned, most of secondary data were extracted from the Ecoinvent V2.0 database. Environmental impacts are assessed using the CML 2000 V2 characterization method [10]. The ten following environmental impacts categories are monitored Abiotic depletion, Acidification, Eutrophication, Global warming, Ozone layer depletion, Human toxicity, Fresh water aquatic ecotoxicity, Marine aquatic ecotoxicity, Terrestrial ecotoxicity and Photochemical oxidation.

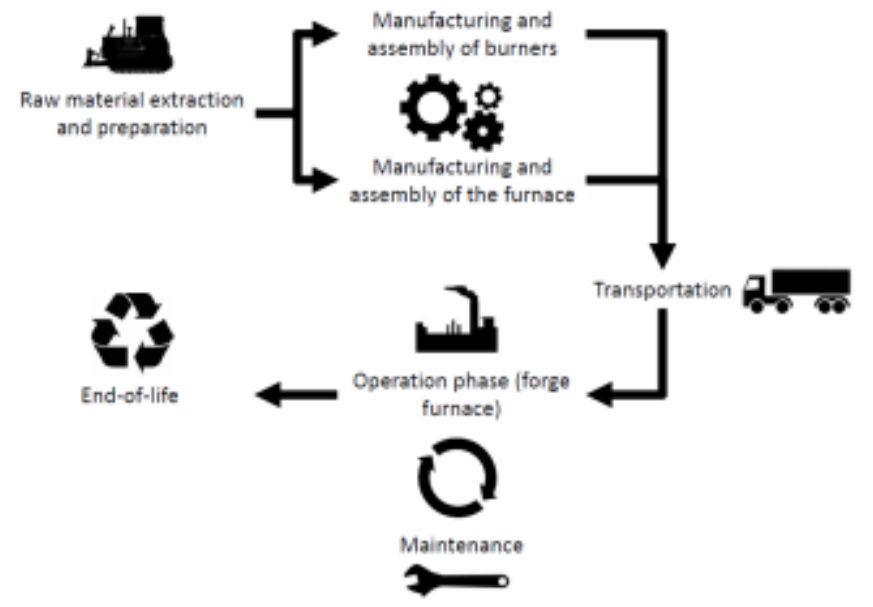

Figure 3. System boundaries

\section{Environmental performance evaluation}

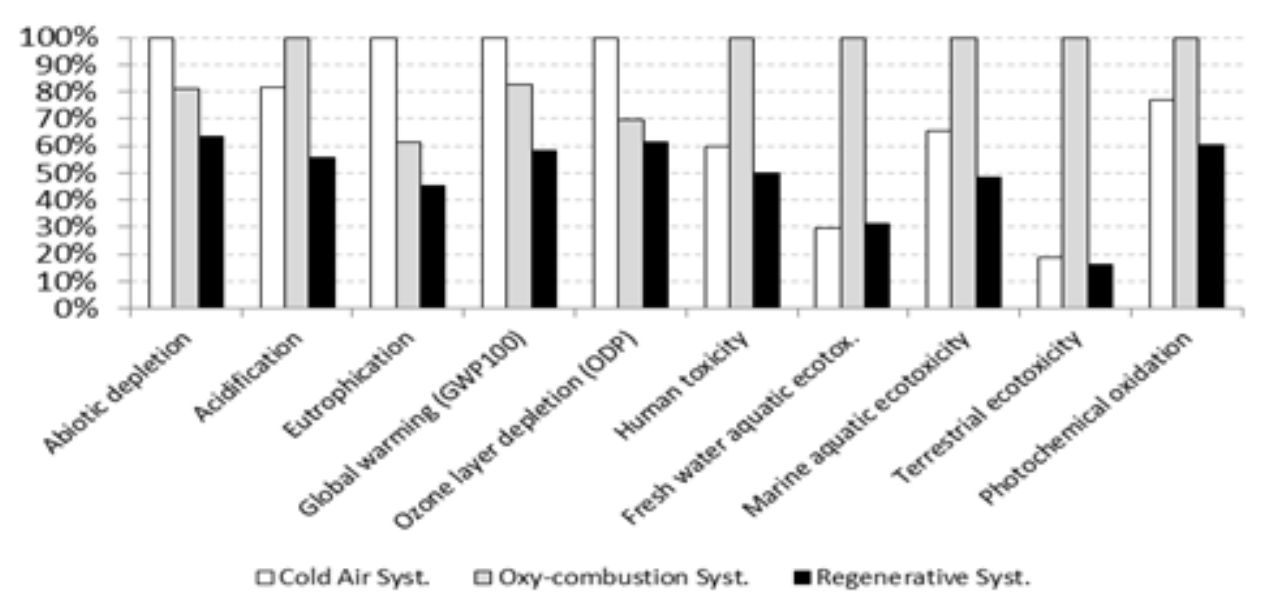

Figure 4. Comparative LCA of three burner technologies for a location in United States

The best solution from an environmental point of view seems to be the regenerative system which is ranked first for most of impact categories (except for Fresh Water aquatic Ecotox). The worst position is shared between the cold air system and the oxy-combustion as depicted in Figure 4.

Once the global environmental impact is broken down according to life cycle phases, the three eco-profiles are quite similar. Indeed, the operational phase is responsible for the main part of environmental impact (see Table 2), which is in accordance with previous LCA studies on energy-consuming industrial systems [1]. The other life cycle phases often present low contribution. However, several impacts categories are more sensitive to these phases, especially to the manufacturing and the maintenance phase. Except for 
Ozone Layer Depletion, the categories of interest deal with toxicity (human toxicity, eco-toxicity, fresh water eco-toxicity). All of these significant impacts occur due to raw material extraction and preparation.

The same situation is observed with the maintenance phase, which substitutes specific components that require resources consumption. In addition, the impacts of the operational phase are due to the electricity consumption (fan and oxygen production) and the natural gas consumption (feed burners). Impacts related to the EOL are low despite the annual maintenance cycle for furnace components. This can be explained by the simplified EOL scenario (steel collection and recycling) where most of materials collected are landfilled.

\begin{tabular}{l|lll}
$\begin{array}{c}\text { Life cycle } \\
\text { Phases }\end{array}$ & Cold air Syst. & $\begin{array}{c}\text { Oxy- } \\
\text { combustion } \\
\text { Syst. }\end{array}$ & $\begin{array}{c}\text { Regenerative } \\
\text { Syst. }\end{array}$ \\
\hline Manufacturing & {$[0.1-15.5 \%]$} & {$[0.2-4.6 \%]$} & {$[0.2-15.2 \%]$} \\
Transportation & {$[0.1-0.8 \%]$} & {$[0.1-1.0 \%]$} & {$[0.1-1.3 \%]$} \\
Operation & {$[92.4-99.9 \%]$} & {$[97.7-99.8 \%]$} & {$[85.4-99.7 \%]$} \\
EOL & {$[-8.5--0.1 \%]$} & {$[-2.7--0.1 \%]$} & {$[-1.2--0.1 \%]$} \\
\hline
\end{tabular}

Table 2. Range of contribution to environmental impacts in respect with the Life Cycle Phase (United States location)

\section{Scenarios modeling}

According to the LCA results, energy and resources consumption during the operation phase are the most impacting elements of the life cycle. Costs associated to these resources (electricity cost in particular) may also be very variable from one country to another.

That is why four countries differing from their location (United States, France, Germany and Japan), their energetic mixes, their supply of natural gas and from EOL performances are chosen to illustrate this study. Considering these four countries and the three alternatives technologies previously described, twelve scenarios are thus considered in the following analyses. As mentioned in the overview of the methodology, costs are then associated to these scenarios. 


\begin{tabular}{|c|c|c|c|c|c|c|}
\hline & & Material & Unit & Cold Air System & $\begin{array}{c}\text { Oxycombustion } \\
\text { system }\end{array}$ & Regenerative System \\
\hline \multirow[t]{12}{*}{ Components } & Furnace & Steel & $\mathrm{kg}$ & 18665.33 & 18665.33 & 18665.33 \\
\hline & & $\begin{array}{l}\text { Refractory (Roof and } \\
\text { walls) }\end{array}$ & $\mathrm{kg}$ & 3175.15 & 3175.15 & 3175.15 \\
\hline & & $\begin{array}{l}\text { Refractory (bottom } \\
\text { part of walls) }\end{array}$ & $\mathrm{kg}$ & 19368.39 & 19368.39 & 19368.39 \\
\hline & & $\begin{array}{l}\text { Refractory (Furnace } \\
\text { Hearth) }\end{array}$ & $\mathrm{kg}$ & 204.12 & 204.12 & 204.12 \\
\hline & & Refractory (chimney) & $\mathrm{kg}$ & 2721.55 & 2721.55 & 2721.55 \\
\hline & Burners & Steel & $\mathrm{kg}$ & 122.47 & 122.47 & 1197.48 \\
\hline & & Controls panel & $\mathrm{kg}$ & 9.07 & 9.07 & 9.07 \\
\hline & & Computers & Unit & 10.00 & 10.00 & 10.00 \\
\hline & & Refractory tile & $\mathrm{kg}$ & 40.82 & 40.82 & - \\
\hline & & Refractory & $\mathrm{kg}$ & - & - & 1678.29 \\
\hline & & Refractory fibers & $\mathrm{kg}$ & - & - & 18.14 \\
\hline & & Regenerative media & $\mathrm{kg}$ & - & - & 675.85 \\
\hline \multirow[t]{5}{*}{ Manufacturing } & Furnace & Welding of furnace & $m$ & 228.59 & 228.59 & 228.59 \\
\hline & & Refractory assembly & btu & 18000000.00 & 18000000.00 & 18000000.00 \\
\hline & & $\begin{array}{l}\text { Wastewater } \\
\text { treatment }\end{array}$ & $\mathrm{cu} \mathrm{ft}$ & 35.00 & 35.00 & 35.00 \\
\hline & Burners & welding of Burners & $m$ & - & - & 50.00 \\
\hline & & Refractory assembly & $\begin{array}{l}\text { gal } \\
\text { (US } \\
\text { liq) }\end{array}$ & - & - & 55.00 \\
\hline Transportation & Road & & $\mathrm{tkm}$ & 165000.00 & 165000.00 & 165000.00 \\
\hline \multirow[t]{10}{*}{$\begin{array}{l}\text { Operation (1 } \\
\text { year) }\end{array}$} & $\begin{array}{l}\text { Energy } \\
\text { consumption } \\
\text { (Year) }\end{array}$ & Electricity for fan & $\mathrm{kg}$ & 48000.00 & 0.00 & 79740.00 \\
\hline & & Fuel & btu & 18200000000.00 & 10920000000.00 & 10920000000.00 \\
\hline & & Control panel & $\mathrm{kWh}$ & 28908.00 & 28908.00 & 28908.00 \\
\hline & $\begin{array}{l}\text { Consumption } \\
\text { (year) }\end{array}$ & Oxygen & $\mathrm{kg}$ & - & 816466.27 & - \\
\hline & $\begin{array}{l}\text { Emissions to } \\
\text { the air (year) }\end{array}$ & Nox & $\mathrm{kg}$ & 1238.31 & 45.36 & 306.17 \\
\hline & & $\mathrm{CO}$ & $\mathrm{kg}$ & 82.55 & 82.55 & 90.72 \\
\hline & & $\mathrm{CO} 2$ & $\mathrm{t}$ & 1066.00 & 619.00 & 555.00 \\
\hline & $\begin{array}{l}\text { Maintenance } \\
\text { (year) }\end{array}$ & Refractory fibers & $\mathrm{kg}$ & 1058.38 & 1058.38 & 1058.38 \\
\hline & & Furnace Hearth & $\mathrm{kg}$ & 19050.88 & 19050.88 & 19050.88 \\
\hline & & Regenerative media & $\mathrm{kg}$ & - & - & 181.44 \\
\hline \multirow[t]{6}{*}{ End-of-Life } & Furnace & Steel & $\mathrm{kg}$ & $?$ & $?$ & $?$ \\
\hline & & Refractory fibers & $\mathrm{kg}$ & $?$ & $?$ & $?$ \\
\hline & & $\begin{array}{l}\text { Refractory furnace } \\
\text { hearth }\end{array}$ & $\mathrm{kg}$ & $?$ & $?$ & $?$ \\
\hline & Burner & Steel & $\mathrm{kg}$ & $?$ & $?$ & $?$ \\
\hline & & Refractory & $\mathrm{kg}$ & $?$ & $?$ & $?$ \\
\hline & & Regenerative media & $\mathrm{kg}$ & - & - & $?$ \\
\hline
\end{tabular}

Table 1: Life Cycle Inventory 


\section{Costs evaluation}

As economics is of high interest in the decision-making process, a costs evaluation is performed to characterize each scenario, i.e. each solution according to the geographical location. To do so, CAPEX and OPEX are investigated. CAPEX are similar for each context while OPEX are sensitive to specific market prices and resource availability, illustrated by Figure 5. An example for US is given in Table 3 and explained in the next paragraph. The reasoning is the same for the three other locations (France, Japan and Germany). The average American energy mix was considered in this part. Consequently prices are based on 2012 prices for electricity, gas and liquid oxygen, in the US, in the industrial sector [11]. The simulation is based on the assumption that these energy mix and prices are constant during the lifespan of the equipment which is assumed to be 25 years.

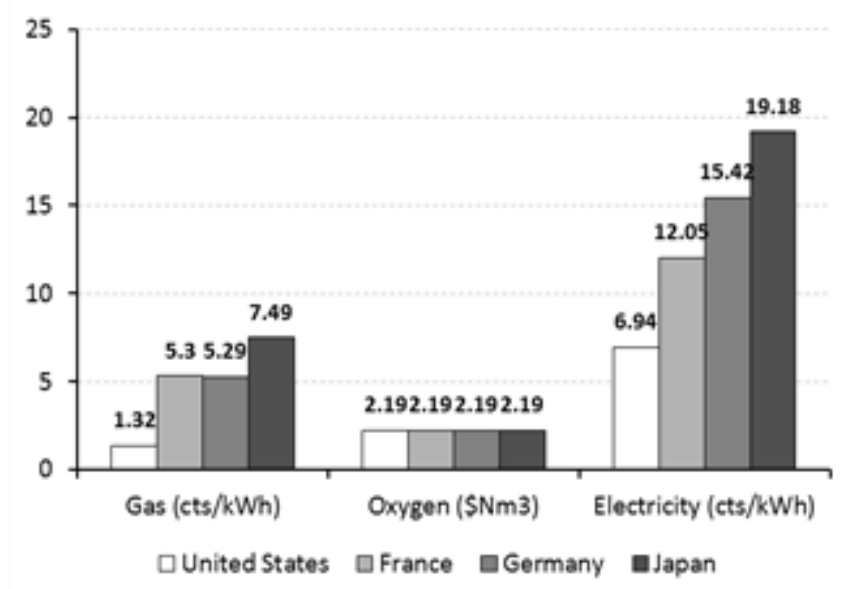

Figure 5. Prices of energy sources according to the operational location

\begin{tabular}{lcrrrr} 
& Components & Unit & Cold Air System & $\begin{array}{c}\text { Oxy-combustion } \\
\text { System }\end{array}$ & $\begin{array}{c}\text { Regenerative } \\
\text { System }\end{array}$ \\
\hline Investment & Furnace & $\$$ & 1000000 & 1000000 & 1000000 \\
& Burner & $\$$ & 150000 & 100000 & 300000 \\
& Total & $\$$ & 1100000 & 1100000 & 1400000 \\
\hline Operation (/ year) & Gas & $\$$ & 70407 & 42244 & 42244 \\
& Oxygen & $\$$ & - & 1251191 & - \\
& Electricity & $\$$ & 5337 & 2006 & 7540 \\
& Total/year & $\$$ & 75745 & 1295441 & 49785 \\
\hline \multicolumn{2}{c}{ Total cost on 25 years } & $\$$ & 3043620 & 33486036 & 2544615
\end{tabular}

Table 3. Costs decomposition for the three burner technologies (United States location)

Investment costs were given by FIVES and are dependent on the size of the installation. An average value was chosen. Cost of maintenance is not taken into consideration in this study.

From the results shown in Table 3, it seems clear that if used in the same context (without any specific technical need, e.g. higher temperature, regulatory limitations, or NOx limitations) the Oxy-combustion System would not be selected. Indeed, operational cost is 10 times higher than that of the two other technologies.

The choice between cold air and regenerative technologies comes down to make a decision between higher investment costs or lower total life-cycle costs. Return on over-investment for regenerative over cold air (time after which the total cost of the regenerative system becomes cheaper) is almost 5.8 years (see Table 
3). On the whole life-cycle, the regenerative system is $16 \%$ cheaper than the cold air system. But for such duration, uncertainties on energy and gas prices are high.

Later on, for scenario building and analysis, oxygen prices are the same for all locations due to the lack of available price data.

The same analysis process is applied on the three other locations (France, Germany, Japan), with similar results, but it is not detailed in this paper.

\section{Generation of Clients' profiles}

As clients may change their preferences according to their own values system, the most relevant technological solution may be different according to the client's profile. In order to integrate such a dimension, three clients' profiles are built. For each of them, economic and environmental aspects are ranked and weighted according to their value perception. The following clients' profiles are presented in Table 4:

Client 1: Short-term economic vision, no environmental consideration;

Client 2: Long-term economic vision, environmental awareness;

Client 3: Long-term economic vision, environmental champion.

\begin{tabular}{l|r|r|r} 
Parameter & Client 1 & Client 2 & Client 3 \\
\hline Capex & 10 & 10 & 10 \\
Opex & 5 & 10 & 10 \\
Global warming potential & 2 & 5 & 10 \\
Ozone layer depletion & 0 & 2 & 5 \\
Human toxicity & $0 \square$ & 2 & 5 \\
Fossil depletion & 0 & 2 & 5 \\
Recycling/reuse & 0 & 5 & 10 \\
\hline
\end{tabular}

Table 4. The three clients' profiles considered

Each score is weighted on a maturity scale from 0 to 10,0 corresponding to 'no consideration' and 10 to 'high consideration'. Considering results aforementioned, the environmental profiles are essentially due to gas consumption, electricity (fan and oxygen production) and natural gas in all cases. They contribute essentially to the Global warming potential (Electricity production and $\mathrm{CO}, \mathrm{CO} 2$ combustion emissions), the Ozone layer depletion (Electricity and Gas production), the Human toxicity (Electricity production and NOx emissions) and the Fossil depletion (Gas production). That is why these four impact categories only are taken into account in the rest of the paper, in order to make it clearer. Raw materials consumption is also of high interest while considering maintenance cycles. In order to integrate such an issue, the parameter Recycling/reuse is integrated. It takes into consideration average recycling rate for each country [12][13]. According to industrial data, solely steel is recovered when refractory parts are landfilled. Maintenance cycles are assessed through both fossil depletion and recycling/reuse indicators.

Once populated, Client's expectations are used to weight economic and environmental values. From this process, a comprehensive ranking of the three technological solutions is obtained.

\section{Results}

Results of economic and environmental simulations are obtained for each of the four countries of interest, e.g. United States, Japan, France and Germany. These locations were chosen because of their specific energy mixes (electricity production), their accessibility to natural gas and their specific End-of-Life treatments. The seven parameters aforementioned are evaluated for the three clients' profiles as reported 
in Table 5. Results are expressed in relative values compared to the Cold Air System which is taken as the baseline. Once normalized, results are weighted with respect to the client's preferences (also normalized in $\%$, see the column 'rate of importance' in Table 5). A single value for each parameter is then obtained. In addition, an aggregated value is calculated as the sum of these single values in order to rank the three technological solutions.

In the case of the client's profile 3, Long-term economic vision and environmental champion, economic issues (CAPEX and OPEX), Global warming potential and EOL (recycling rate) are of high importance for the decision-making (18.2\%) (see Table 5). The four other supervised variables, Ozone depletion, Human toxicity, Abiotic depletion and Recycling/reuse are of minor importance. A slight difference is observed for the CAPEX between the forge furnace equipped with the baseline and the forge furnace equipped with the Regenerative System, the obtained value is equal to 0.05. In contrast, values for OPEX are quite different. These negative values present lower operational costs for the regenerative solution. Indeed, lower amounts of fuel and electricity are consumed during the 25 years exploitation phase. Results are similar regardless the specific location. Focusing on environmental impact categories, all values are negative. This suggests that the Regenerative System has higher environmental performances. This solution presents a better value for the Ozone depletion in the Japanese context. This is caused by the specific natural gas supply and the energy mix which generate fewer impacts than for the other locations. The recycling variable also supports the Regenerative System. Although the quantity of raw materials consumed is higher for this solution (construction and maintenance), the eco-profile is balanced thanks to a higher amount of recyclable materials. Finally, an aggregated value is calculated for all countries in order to overcome undecidable situation. In the example reported in Table 5, the Regenerative Solution is preferred for the four countries considered, France, Germany, United States and Japan. The aggregated indicator is used to allow the decision maker to combine all variables and shed light on the decision. In the Japanese case, the most relevant technological solution is still the Cold Air System.

Figure 6 provides additional results combining the specific location, the economic and environmental performances and the client's profiles. As aforementioned, results are expressed in relative values and are normalized compared to the Cold Air System (baseline). The tornado diagrams report the overall performance (aggregated value) of each technological solution per client's expectations and per country. So, if values are positive, the Cold Air System is defined as the most relevant solution. In the opposite, if values are negative, the alternative solution is preferred. In addition a comparison between the Regenerative System and the Oxy-combustion System is possible. The three clients' profiles integrate the specific values system (see Table 4) and allow positioning of the technological solutions according to their expectations. Results for all countries, lead to similar conclusions. The ranking of the three technological solutions favors the implementation of the Regenerative System with respect to the clients' profiles 2 and 3, integrating both environmental considerations into the decision-making process. In this context, the Oxy-combustion System is perceived as the worst solution. In opposite, the client's profile 1 suggests preferring the Cold Air System even if results compared to the Regenerative solution are very close. Indeed, the Regenerative solution presents lower gas consumption during the operational phase than the baseline. Considering the Oxycombustion system, the main additional impact comes from the liquid oxygen that is consumed which requires a lot of energy to be produced. Even if profiles are similar from one country to another, the slight differences that are observed are connected to the energy prices. Indeed, three trends can be observed, the US situation, the Western Europe situation and the Japanese one respectively. France and Germany provide an intermediate profile. US highly support the Regenerative System and the Cold Air System compared to the Oxy-fuel System. Results for Japan are closer and the superiority of both alternatives compared to the Oxy-Fuel System is attenuated. The main explications come from the global environmental impacts and the energy costs (production and transportation). Indeed, Japan provides the highest environmental impacts for the three considering the four countries. The economic issue reveals the same trends while observing the costs of gas and electricity (see Figure 5). In the case of clients' profile 1, e.g. without any environmental consideration, the Regenerative System appears as competing with the baseline. The consideration of environmental impacts categories, e.g. profiles 2 and 3, decreases the performances of the two alternative technological solutions. In consequence, the more environmental issues that are integrated into the decision-making, the more the Regenerative System is attractive. 


\begin{tabular}{rrllrrrr}
$\begin{array}{l}\text { Rate of } \\
\text { Importance }\end{array}$ & Weighting & Parameters & Unit & France & Japan & \multicolumn{2}{c}{ United } \\
\hline $18.2 \%$ & 10 & Capex & US $\$$ & 0.050 & 0.050 & 0.050 & Germany \\
\hline $18.2 \%$ & 10 & Opex & US $\$$ & -0.068 & -0.067 & -0.062 & -0.067 \\
& & Global warming & kg CO2 eq & & & & \\
$18.2 \%$ & 10 & potential & & -0.078 & -0.077 & -0.076 & -0.077 \\
$9.1 \%$ & 5 & Ozone layer depletion & kg CFC-11 eq & -0.035 & -0.019 & -0.035 & -0.035 \\
$9.1 \%$ & 5 & Human toxicity & kg 1,4-DB eq & -0.022 & -0.025 & -0.015 & -0.025 \\
$9.1 \%$ & 5 & Abiotic depletion & kg Sb eq & -0.034 & -0.034 & -0.033 & -0.033 \\
$18.2 \%$ & 10 & Recycling & kg & -0.225 & -0.225 & -0.225 & -0.225 \\
\hline $\mathbf{1 0 0 . 0 \%}$ & & & & $-\mathbf{0 . 4 1 2}$ & $\mathbf{- 0 . 3 9 7}$ & $\mathbf{- 0 . 3 9 7}$ & $\mathbf{- 0 . 4 1 2}$
\end{tabular}

Table 5. Detailed results for the Regenerative System (Client's profile 3)

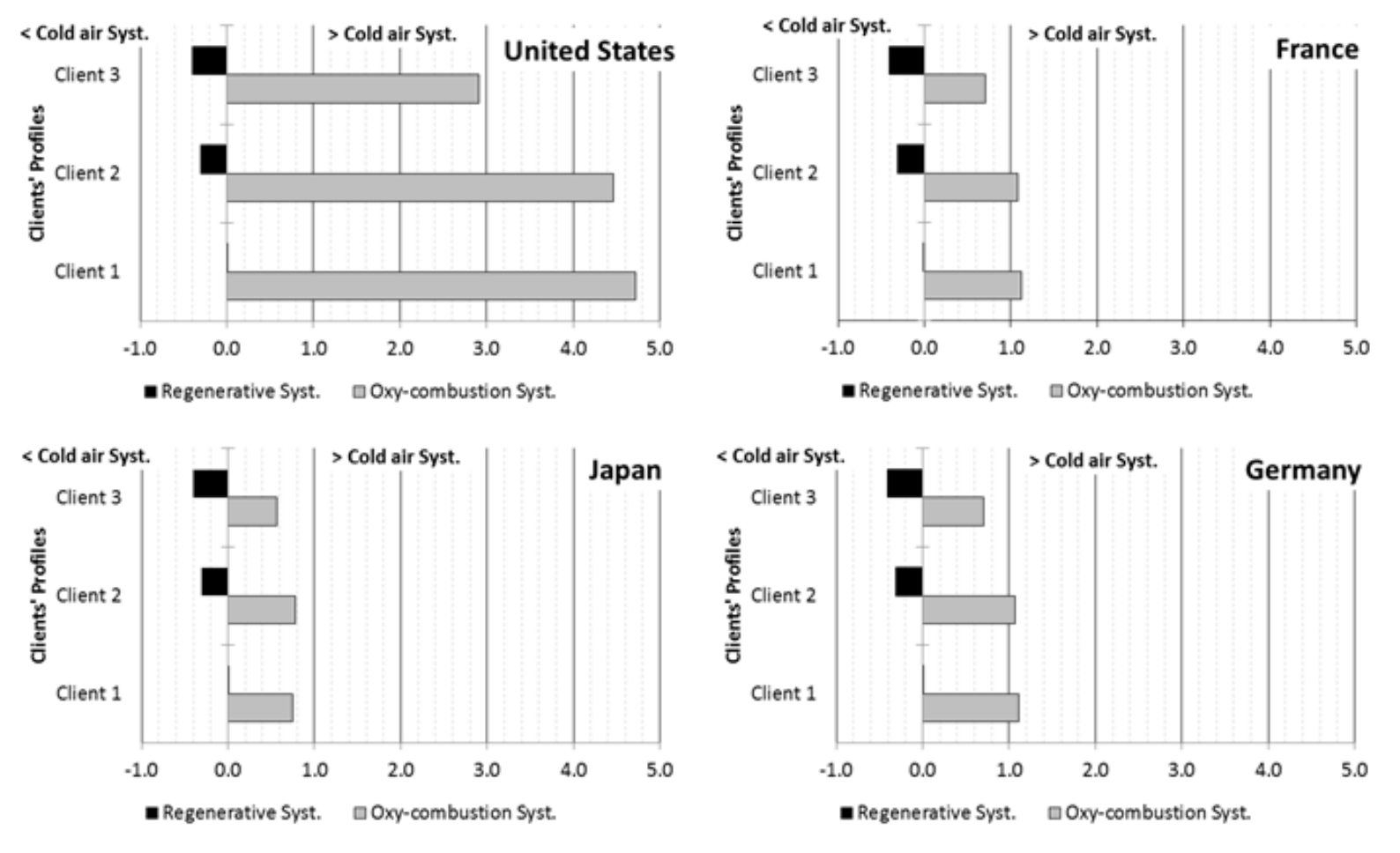

Figure 6. Results based on the final single score for the three clients' profiles, the three alternatives systems and the four locations. The Cold Air System is taken as reference.

\section{Discussion}

In this paper the performances of three technological solutions of burner for a forge furnace are investigated. Environmental profiles are drawn thanks to LCA while economic issues are dealt with through CAPEX and OPEX calculation.

Results highlight several issues when dealing with decision-making under sustainable considerations. First, comparative LCA of technological solutions are often performed considering generic models and databases. Thus, variability caused by local situations is erased and a ranking of solutions can be easily obtained. Nevertheless, local context may highly affect the environmental performances. It is quite important to consider local variables until they integrate resources availability and accessibility, local or regional energy mixes and specific production processes. Consequently, there is a real need for detailed analysis to overcome simplifications in generic models for such application. 
Second, sustainable decision cannot focus exclusively on the environmental dimension. Economic issues and client's expectations are of high importance in the decision-making process[2]. Even if simple, the integration of both CAPEX and OPEX provides useful information to the decision-maker in a life cycle approach while long-term and short-term visions can be handled. Coupling such economic and environmental results with client's expectations facilitate technological choices. While some clients are sensitive to environmental considerations, others are not. The knowledge about the client's preferences can shed light on the decision-making by identifying the most relevant and adapted solution. Results from Figure 6 support this fact. Indeed, in all countries, the most relevant solution for client 1 is the Cold Air System. The increasing integration of environmental aspects in client's profiles 2 and 3, provides a new ranking. Indeed, a reversal between the baseline and the Regenerative System is observed.

The modeling approach also points out several issues and limitations. First, both environmental and economic modeling and simulations are static. The market price evolution for gas and electricity, the energetic mix composition, the demand on raw materials that may highly impact operational costs are excluded from the study. In addition, technological evolutions of local production processes that may contribute to reduced environmental burdens are also excluded. The same assumption was also defined regarding the regulatory context. These limitations provide ways of improvement towards more robust simulations.

Limitations can be observed on data availability and data relevancy. Indeed, LCA requires a lot of information. Most of them are extracted from LCl databases which have uncertainty about data completeness and relevancy [14][15]. In the case study, particular attention was paid to data collection and data selection. However data are still lacking, in particular about the Oxy-combustion System. The price of such a technology is an example. In order to account for the lack of knowledge, the same price was assumed for the liquid oxygen whatever the country considered.

Finally, the methodology is based on multi-criteria analysis. LCA may focus on a single impact category, such as the Global Warming Potential for example, or more. The number of impact categories was reduced from ten (Figure 4) to four (Figure 6) in the case study. This simplification was performed in order to ease the interpretation. These categories were chosen with respect to the sensitivity analysis. Nevertheless this limitation provides a good way to enrich the case study in future works.

Furthermore, the ranking of the technological solution is based on weighting factors extracted from client's expectations. Knowing that multi-criteria analysis can lead to undecidable decision, an aggregated score was also calculated consisting in the sum of economic and environmental weighted values. Results can be consolidated through the implementation of more consistent multi-criteria approaches [16]. This would increase the robustness of such a decision-making process.

Finally another improvement direction could be the consideration of uncertainty intervals as close results are often not sufficient to make a reliable decision. Several quantitative or qualitative uncertainty methods, such as intervals propagation, Monte Carlo simulations, Bayesian Monte Carlo Approach could be easily implemented to enrich the proposed approach [17][18][19].

\section{Conclusions and perspectives}

We have proposed in this paper a framework to assess the sustainable performance of industrial systems by the inclusion of environmental, economic, commercial and local aspects. This approach is based on LCA of different technological alternatives. A first LCA is performed to identify the most relevant parameters and thus to generate a set of exploitation scenarios associated with different geographical locations. Once the environmental profiles of these scenarios are identified, economic costs, based on OPEX and CAPEX, are associated. The consideration of different clients' profiles, corresponding to different industrial positions, then permits a relative and weighted performance of an alternative solution compared to a predefined reference, for the selected indicators (e.g. costs or environmental impact categories). The analysis of these indicators may be sufficient for decision-making; however for some configuration it is not possible. That is why we proposed an aggregated indicator that may be useful to support decision.

Applied to burner technologies for forge furnace, this framework show that local context data are essential to assess the sustainability of industrial system and to make reliable decisions. Indeed in some cases the use of generic data may lead to false results and wrong decisions.

Even if this model would be improved, for example by refining and completing data, it clearly shows the necessity to carefully define a relevant context when assessing the sustainability of industrial systems. Future works could consider other industrial case studies or take into account more structured uncertainty or decision-making methods and tools to propose an improved sustainability assessment framework. 


\section{Acknowledgments}

The authors are grateful to FIVES group, our industrial partner, and especially to Pauline Plisson, Gonzalez Aurélie (Fives Holding) and Justin Dzik (Fives North American Combustion) for providing the case study and related data.

\section{References}

[1] F. Cluzel, B. Yannou, D. Millet, and Y. Leroy, "Exploitation scenarios in industrial system LCA," Int. J. Life Cycle Assess., vol. 19, no. 1, pp. 231-245, 2014.

[2] G. a. Norris, "Integrating Economic Analysis into LCA," Environ. Qual. Manag., vol. 10, no. 3, pp. 59-64, 2001.

[3] A. D. Smith and P. J. Mago, "Economic, Emissions, and Energy Benefits From Combined Heat and Power Systems by Location in the United States Based on System Component Efficiencies," in Volume 6A: Energy, 2013, p. V06AT07A034.

[4] E. Sundin, M. Lindahl, and H. Larsson, "Environmental and economic benefits of industrial product/service systems," Proc. CIRP Ind. Prod. Syst., pp. 91-98, 2010.

[5] A. Widiyanto, S. Kato, and N. Maruyama, "A LCA/LCC Optimized Selection of Power Plant System With Additional Facilities Options," J. Energy Resour. Technol., vol. 124, no. 4, p. 290, 2002.

[6] K. Masui, T. Sakao, S. Aizawa, and A. Inaba, "Quality Function Deployment for Environment (QFDE) to Support Design for Environment (DFE)," in Volume 3: 7th Design for Manufacturing Conference, 2002, vol. 2002, pp. 415-423.

[7] International Standards Organization, ISO 14040: Environmental management - life cycle assessment - principles and framework. ISO 14040:2006(E). 2006.

[8] International Standards Organization, ISO 14044: Environmental management - life cycle assessment - requirements and guidelines. ISO 14044:2006(E). 2006.

[9] R. Frischknecht, N. Jungbluth, H. Althaus, G. Doka, R. Dones, T. Heck, S. Hellweg, R. Hischier, T. Nemecek, G. Rebitzer, and M. Spielmann, "ecoinvent: Introduction The ecoinvent Database : Overview and Methodological Framework," Int. J. Life Cycle Assess., vol. 10, no. 1, pp. 3 - 9, 2005.

[10] J. Guinée, M. Gorrée, R. Heijungs, G. Huppes, R. Kleijn, L. Oers van, A. Wegener Sleeswijk, S. Suh, H. Udo de Haes, H. de Bruijn, R. Duin van, and M. Huijbregts, Life Cycle Assessment: An Operational Guide to the ISO Standards. Dordrecht (NL): Kluwer Academic Publishers, 2002.

[11] Eurostat and IEA, "Industrial electricity prices in the EU and G7 countries," 2013. [Online]. Available: https://www.gov.uk/government/statistical-data-sets/international-industrial-energyprices. [Accessed: 22-Jan-2014].

[12] Steel Recycling Institute, "Steel recycling rates in the US," 2013. [Online]. Available: http://www.recycle-steel.org. [Accessed: 20-Nov-2013].

[13] World Steel Association, "No Titl." [Online]. Available: http://www.worldsteel.org/. [Accessed: 17Nov-2013].

[14] A. E. Björklund, "Survey of approaches to improve reliability in Ica," Int. J. Life Cycle Assess., vol. 7, no. 2, pp. 64-72, Mar. 2002.

[15] Y. Leroy, "Development of a Methodology to Reliable Environmental Decision from Life Cycle Assessment Based on Analysis and Management of Uncertainty on Inventory Data," ENSAM, 2009.

[16] J.-J. Wang, Y.-Y. Jing, C.-F. Zhang, and J.-H. Zhao, "Review on multi-criteria decision analysis aid in sustainable energy decision-making," Renew. Sustain. Energy Rev., vol. 13, no. 9, pp. 22632278, Dec. 2009.

[17] S. Lo, H. Ma, and S. Lo, "Quantifying and reducing uncertainty in life cycle assessment using the Bayesian Monte Carlo method," Sci. Total Environ., vol. 340, pp. 23 - 33, 2005.

[18] S. M. Lloyd and R. Ries, "Characterizing, Propagating, and Analyzing Uncertainty in Life-Cycle Assessment: A Survey of Quantitative Approaches," J. Ind. Ecol., vol. 11, no. 1, pp. 161-179, 2007.

[19] Y. Leroy and D. Froelich, "Qualitative and quantitative approaches dealing with uncertainty in Life Cycle Assessment ( LCA ) of complex systems: towards a selective integration of uncertainty according to LCA objectives," Int. J. Des. Eng., vol. 3, no. 2, pp. 151-171, 2010. 